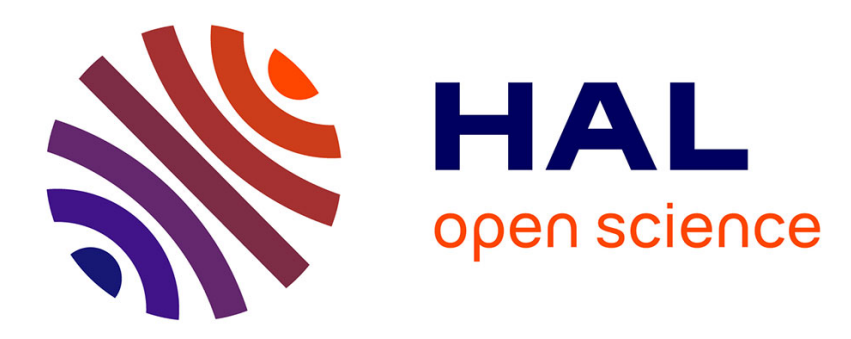

\title{
Chiral Cobalt-Salen Complexes: Ubiquitous Species in Asymmetric Catalysis
}

Emmanuelle Schulz

\section{To cite this version:}

Emmanuelle Schulz. Chiral Cobalt-Salen Complexes: Ubiquitous Species in Asymmetric Catalysis. Chemical Record, 2021, 21 (2), pp.427-439. 10.1002/tcr.202000166 . hal-03292254

\section{HAL Id: hal-03292254 \\ https://hal.science/hal-03292254}

Submitted on 20 Jul 2021

HAL is a multi-disciplinary open access archive for the deposit and dissemination of scientific research documents, whether they are published or not. The documents may come from teaching and research institutions in France or abroad, or from public or private research centers.
L'archive ouverte pluridisciplinaire HAL, est destinée au dépôt et à la diffusion de documents scientifiques de niveau recherche, publiés ou non, émanant des établissements d'enseignement et de recherche français ou étrangers, des laboratoires publics ou privés. 


\section{Chiral cobalt-salen complexes :} ubiquitous species in

\section{asymmetric catalysis}

Emmanuelle Schulz ${ }^{*[a]}$

Dedicated to P.H. Dixneuf for his outstanding contribution to organometallic chemistry and catalysis

[a] Title(s), Initial(s), Surname(s) of Author(s) including Corresponding Author(s)

Department

Institution

Address 1

E-mail:

[b] Title(s), Initial(s), Surname(s) of Author(s)

Department

Institution

Address 2

Supporting information for this article is given via a link at the end of the document.((Please delete this text if not appropriate)) 
Abstract: Since the discovery of their extraordinary reactivity in the hydrolytic kinetic resolution of terminal epoxides about twenty years ago, chiral Co-salen complexes have been shown to be essential for many other asymmetric catalytic reactions. This account summarizes the inspiring works dedicated to the discovery of their new reactivity and their mode of action, as well as the new processes towards the optimization of their cooperativity for bimetallic activation and the implementation of their effective immobilization, including also our contribution on these topics.

\section{Introduction}

Asymmetric catalysis promoted by chiral organometallic species has experienced, over the past 50 years, ${ }^{[1]}$ a huge development in terms of mechanistic understanding, application to new reactivities and discovery of new catalytic species. On this last point, however, it is clear that only a limited number of ligands have proven their ability to promote a large number of very diverse reactions with excellent efficiency, allowing them to become mandatory ligands in asymmetric catalysis. The salen ligands ${ }^{[2]}$ belong undoubtedly to this category; those Schiff bases are straightforwardly prepared from the condensation between salicylaldehydes and various optically pure diamines, with the most renown and currently used ligand resulting from the reaction of 5,5'-di-tert-butyl-salicylaldehyde with enantiopure cyclohexane-1,2-diamine, often described as Jacobsen ligand (see 1 in figure 1). ${ }^{[3]}$
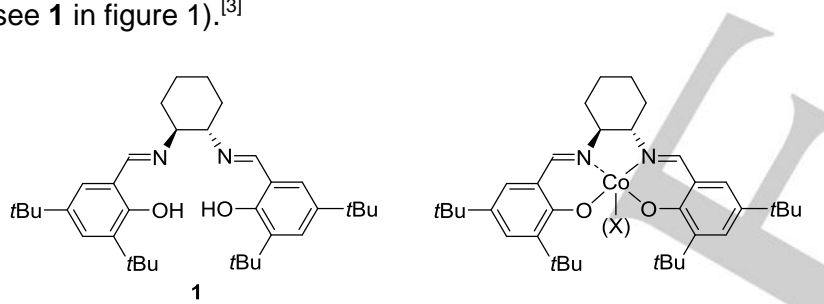

Figure 1. Classical salen ligand, and $\mathrm{Co}(\mathrm{II})$ - and $\mathrm{Co}$ (III)-complexes.

These ligands have given rise to numerous chiral complexes, through reactions with a great diversity of metallic salts, which demonstrated their high efficiency to promote the enantioselective formation of carbon-carbon or carbonheteroatoms bonds. ${ }^{[4]}$ The scope of this mini-review is for from targeting to cover the wide use of such complexes, but it aims to dwell on the reactivity of cobalt-salen complexes for different reasons. Since their discovery as outstanding catalysts for the hydrolytic kinetic resolution of epoxides ${ }^{[5]}$ (vide infra), these cobalt-salen complexes have also proven their ability to promote

[a] Dr. E Schulz

Université Paris-Saclay, CNRS

Institut de Chimie Moléculaire et des Matériaux d'Orsay

91405 Orsay, France

E-mail: emmanuelle.schulz@universite-paris-saclay.fr numerous other transformations with efficiency; this will be shortly reviewed in the first part to show that inspiring and new developments are still in progress. We want further to focus on the seminal work performed by Jacobsen and his group to fine tune optimal reactions conditions with these cobalt species, for the kinetic resolution of terminal epoxides. This transformation was so effective that it is one of the rare examples, except those dealing with hydrogenation reactions, leading to the development of asymmetric organometallic catalysis at the industrial scale. ${ }^{[6]}$ The mechanism of this reaction has been studied in details ${ }^{[7]}$ revealing a bimetallic activation for its completion, in both high yields and excellent enantioselectivity. This discovery then led to the search for new catalytic structures to promote such cooperativity. Thus, many groups have targeted the immobilization of cobalt-salen complexes on various supports, ${ }^{[8]}$ in an attempt to promote this dual activation. Others, including us, prepared homopolymetallic cobalt complexes contained within polymer chains or macrocycles. Cobalt-salen catalysts have furthermore been associated through non covalent interactions leading also to efficient subsequent bimetallic activation. Without being exhaustive, some of these examples will be here described with a specific emphasis on the effect of the catalyst structure on the corresponding bimetallic activation and its importance for the catalytic result.

E. Schulz graduated from ESCIL in Lyon and received her Ph.D. degree in 1992 for studies concerning the total synthesis of Strigol (Pr. P. Welzel, Ruhr-Universität

Bochum/Université de Lyon). After an industrial postdoc (RP Agro), she joined the group of Prof. M. Lemaire in Lyon and obtained a permanent position at the CNRS Since 2000, she has been working in the Institut de Chimie Moléculaire et des

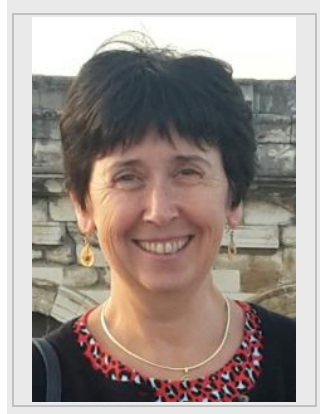

Matériaux d'Orsay (Université Paris Saclay).

Her research interests are mainly directed towards asymmetric catalysis. She particularly explores the enantioselective hydroamination reaction promoted by chiral rare-earth based catalysts. New procedures for the easy recovery and reuse of chiral organometallic catalysts, specifically with enantiopure salen complexes, are also developed in her group.

\section{Cobalt-salen complexes, as multi-purpose catalysts}

Cobalt-salen complexes are obviously renowned for their extraordinary activity in kinetic resolutions and this will be discussed in the next part of this account. However, they are also capable of promoting many other asymmetric catalytic reactions due to their pronounced Lewis acid character. Some of them will be listed as follows, by beginning with a quite atypical use of salen complexes; cobalt-salen catalysts have indeed been demonstrated to promote the transhydrogenation of acetophenone, particularly in a heterogeneous manner when 
entrapped in a zeolite. ${ }^{[9]}$ The modified solid support was prepared via a "ship-in-the-bottle" procedure, with the encapsulation of the chiral cobalt complex leading to enantioselectivity values matching those obtained under analogous homogeneous conditions. Also, Katsuki and coworkers reported that cobalt-salen complexes catalyzed the asymmetric Baeyer-Villiger reaction of 3-substituted cyclobutanones with $\mathrm{H}_{2} \mathrm{O}_{2}$ as terminal oxidant, provided that the complex bore two vicinal open coordinating-sites. ${ }^{[10]}$ More recently, formation of new $\mathrm{C}-\mathrm{N}$ bonds was demonstrated by the use of cobalt-salen complexes to catalyze the enantioselective Michael addition of amines to $\beta$-substituted nitroalkenes. ${ }^{[11]}$ With O-alkylhydroxylamine as nucleophiles, optically enriched 1,2nitroamines were prepared in excellent yield and up to $91 \%$ ee. Some interesting results were also obtained via the use of a cobalt salen complex to promote the Darzens condensation between $\alpha$-haloamides and aldehydes. ${ }^{[12]}$ Fine-tuning of the operating conditions, i.e. the nature of the halo-amide and the base, allowed the diastereoselective formation of cis- or transepoxides with enantioselectivity values which however did not exceed $50 \%$.

It is much more likely to find articles dealing with the use of these cobalt complexes for the formation of C-C bonds. Indeed, along with the discovery of their efficiency in the opening reaction of epoxides, Katsuki described their ability to perform cyclopropanation reactions. ${ }^{[13]}$ The preparation of diverse cobalt(III) salen species bearing a bromide or an iodide atom as axial ligand led to very active species, provided that the active site was not crowded by bulky substituents. The most active and enantioselective complexes possess a bromide ligand and electron-donating methoxy group in the para-position (see 2 in Scheme 1). The reaction was performed in the presence of tertbutyl diazoacetate as a carbene source leading to an intermediary non planar carbenoid species, strongly influencing the approach of the incoming olefin.

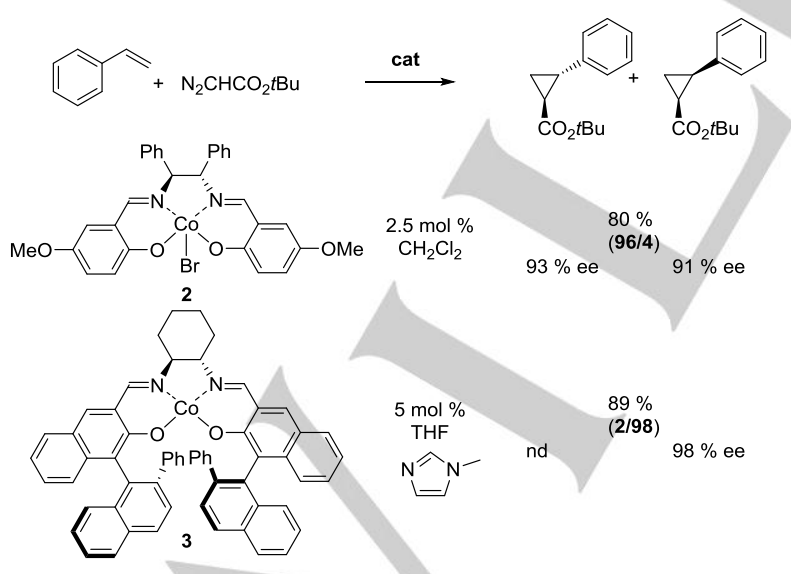

Scheme 1. Asymmetric cyclopropanation of styrene using Co(III)- and Co(II)salen complexes as catalysts.

The Katsuki's group further studied this transformation and they exploited the fact that $\mathrm{Co}$ (II)-salen complexes can easily adopt various ligand conformations, depending on the substituents; they demonstrated that the cyclopropanation reaction depends on the metal ion (with the synthesis of active and selective $\mathrm{Ru}(\mathrm{NO})$-salen complexes), on the structure of the salen ligand (with both steric and electronic effects), and on the nature of the apical ligand. ${ }^{[14]}$ By preparing complex 3 (Scheme 1), they discovered a very active species leading to high cis- and enantio-selectivity. ${ }^{[15]}$ Interestingly, complex $\mathbf{3}$ was easily recoverable after removal of the reaction products with hexane, and reused with no loss of efficiency. ${ }^{[16]}$ These last conditions were suitable to catalyze intramolecular cyclopropanation reactions under high substrate concentration. ${ }^{[17]}$ This reaction is still subject to development and White and Shaw prepared a new Co(II)-salen complex bearing the cis-2,5-diaminobicyclo[2.2.2] octane as chiral backbone ${ }^{[18]}$ which, in the presence of potassium thioacetate as additive, allowed the cyclopropanation reaction to occur from 1,1-disubstituted alkenes in excellent yield, diastereoselectivity and enantioselectivity values. The strategy was successfully applied to the synthesis of (+)-synosutine, a dual inhibitor of serotoninepinephrine reuptake.

Another successful use of cobalt-salen for the formation of C-C bonds is the Diels Alder reaction. Rawal and coworkers indeed reported that $\mathrm{Co}(\mathrm{III})$-salen hexafluoroantimonate complexes promoted the reaction between 1-benzylaminocarbamate-1,3butadiene and various acroleins, which occurred with exceptionally low catalyst loadings (down to $0.05 \mathrm{~mol} \%$ ), provided the presence of very bulky groups generating constraints on the aromatic positions ortho to the phenolic positions of the salen (4, Scheme 2). ${ }^{[19]}$ These authors also discovered that the salen analogue bearing even more sterically hindering triisobutylsilyl groups in these positions were highly efficient to promote the carbonyl-ene reaction of 1,1disubstituted or trisubstituted alkenes and ethylglyoxylate, to afford the corresponding enantioenriched homoallylic products in excellent yields and up to $98 \%$ ee. ${ }^{[20]}$

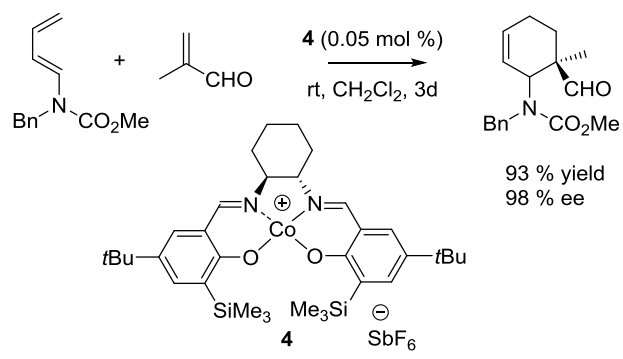

Scheme 2. Asymmetric Diels-Alder reaction using a sterically hindered Co(III)salen complex as catalyst.

Another application of Co(II)-salen complexes can be found in the asymmetric synthesis of $\alpha$-methyl $\alpha$-amino acids under phase transfer catalysis conditions from imines, ${ }^{[21]}$ but also in the formation of scalemic $4 \mathrm{H}$-chromene derivatives with various pharmacological properties, through a tandem Michael additioncyclization reaction. ${ }^{[22]}$ 
This quick overview of the bibliography makes it possible to highlight the wide range of application of cobalt-salen complexes in particular for the formation of C-C bonds. But a specific emphasis must here be drawn towards the Henry reaction, for which many attempts were performed for favoring bimetallic activation. This type of reactivity was initially described by Yamada and his group, in 2004. ${ }^{[23]}$ They proved that the simple $\mathrm{Co}$ (II)-catalyst derived from the Jacobsen ligand (see Figure 1 and Scheme 3) catalyzed the nitro-aldol reaction between various aldehydes and nitromethane to afford $\beta$-hydroxynitroalkanes in both high yield and enantioselectivity in the presence of a tertiary amine as a base. This transformation provides a good benchmark model to study the possible effect of cooperativity between both metallic centers, one activating the carbonyl functionality, the other one, the nitronate ion. In this context, Hong and coworkers constructed bimetallic cobaltspecies through non-covalent interactions. ${ }^{[24]}$ They indeed prepared a dissymmetric salen derivative bearing both a 2pyridone and an aminopyridine functional group, able to selfassemble as dimer in solution through formation of hydrogen bonding pairs (see 6 , representing the dimeric structure in Scheme 3). Control experiments revealed significant rate acceleration using this catalyst as well as kinetic studies indicated a second order relative to the cobalt concentration, with excellent enantioselectivity values for a range of aldehydes (8 examples, up to $96 \%$ ee).

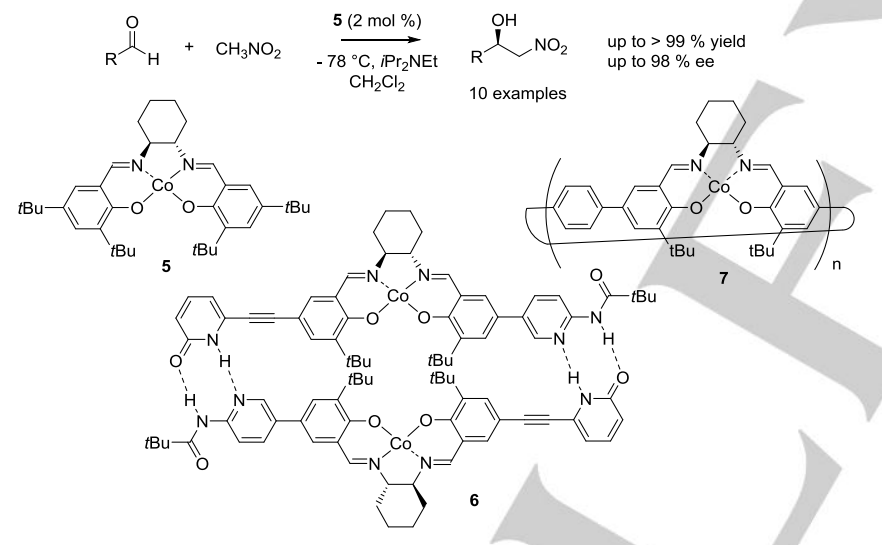

Scheme 3. Enantioselective Nitro-aldol reaction with Co(II)-salen complexes as catalysts.

Synthesis of unsymmetrical salen derivatives is not particularly straightforward and this requires the preliminary monoprotonation of the diamine. ${ }^{[25]}$ Aiming for an easy synthesis we have reported the preparation of chiral macrocycles containing enantiopure salen moieties, named calix-salen, through polycondensation reactions between various disalicylaldehyde derivatives and chiral diamines. According to the concentration of the mixture in the reaction, dimers or tetramers were selectively prepared. ${ }^{[26]}$ Cobalt complexes were then obtained from these ligands (see 7 in Scheme 3 ) by reaction with $\mathrm{Co}(\mathrm{OAc})_{2} \cdot 4 \mathrm{H}_{2} \mathrm{O}$ and the corresponding catalyst was used for the nitro-aldol reaction, as insoluble species in dichloromethane. ${ }^{[27]}$ This property allowed its easy separation from the reaction mixture after the first use and its reuse in four consecutive runs. The reaction proceeded however with low yield and enantioselectivity, probably featuring a non-efficient bimetallic pathway. In contrast, corresponding reduced salen derivatives were prepared and the copper-salan macrocycles were engaged in the same transformation, in the absence of a base, leading to the targeted product in both high yield and enantioselectivity. The insoluble catalyst was efficiently reused for ten recyclings and also engaged in a multi-substrate procedure with a different substrate as each reuse, demonstrating its extreme stability. Such a comparison between Co-salen and Cu-salan complexes was also reported by the group of $\mathrm{Xu}^{\left[{ }^{[28]}\right.}$ They described the preparation of an $\mathrm{Ar}$ BINMOL-derived Co(III)-salen complex delivering high yields and enantioselectivities in the Henry reaction, evidencing specific $\pi-\pi$ stacking interactions between the rotatable $\pi$-walls of the ligand and suitable substrates. Dimroth and Weck prepared both, Co-salen and analogous -salan derivatives as monomers, and also oligomers, obtained by ring-opening metathesis polymerization of salen-based compounds bearing cyclooctene groups (for example, 9 and 10 in Figure 2). ${ }^{[29]}$ The corresponding cyclic structures with the Co(II)-salen moieties attached in a pendent manner led to more active species compared to monomer ones, as a result of a facilitated bimetallic pathway. Furthermore, a reversal in the enantioselectivity of the niotroaldol products was obtained, in a practical way, by using either the salen or the salan derivatives, starting of course from the diamine with the same configuration. The authors proposed the presence of supplementary hydrogen bonds and different steric hindrance around the active sites to explain this unusual phenomenon.

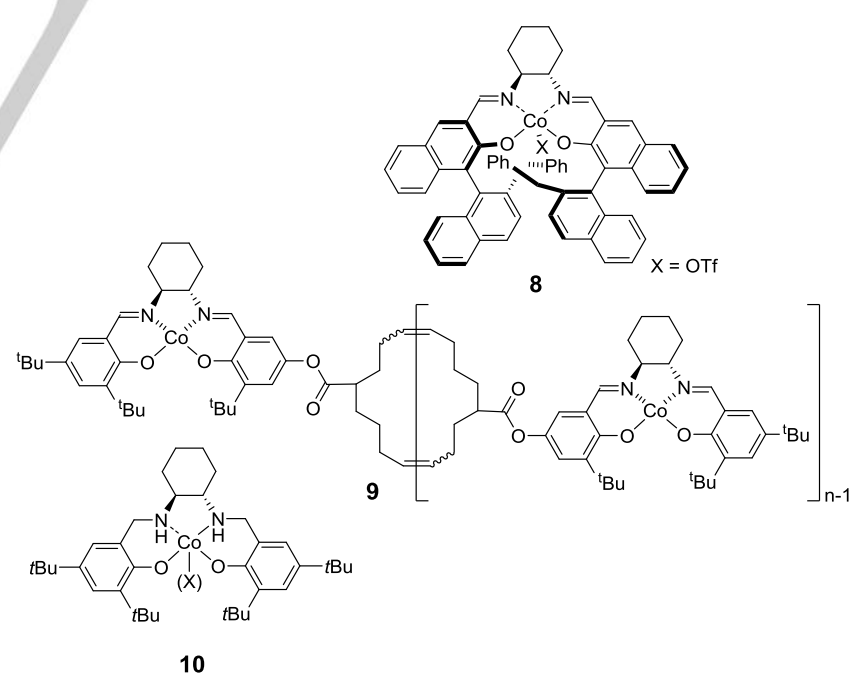

Figure 2. Co(II)- and $\mathrm{Co}(\mathrm{III})$-salen complexes, monomers and oligomers, as catalysts for the Henry reaction.

A very last elegant example of bimetallic Co-salen complexes efficient for the Henry reaction was published recently by 
Yashima and his group, who designed specific salen dimers, prompts for the formation of a complementary double helix. They thus prepared a salen-carboxylic acid dimer, and another one bearing chiral amidine derivatives, arranged on a $m$-terphenyl framework able to construct a complementary double-stranded helical bimetallic catalyst stabilized by amidinium-carboxyalte salt bridges (11 in Figure 3). ${ }^{[30]}$ The double helix proved both more active and enantioselective than each strand taken alone and its role was furthermore proven by the formation of an enantioenriched product, even if the catalyst contained an achiral Co-salen catalyst.

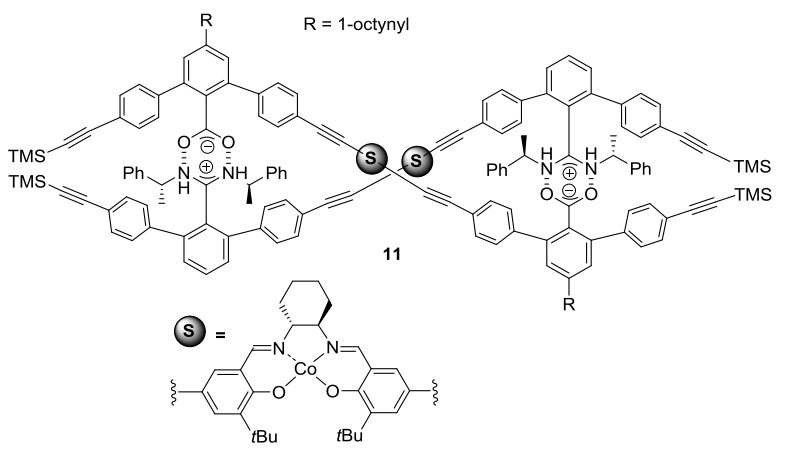

Fidure 3. Double-helical Co(II)-salen framework for enantioselective Nitroaldol reaction.

Also worth-mentioning is the use of cobalt salen derivatives for either the formation of propylene carbonate,$^{[31,32]}$ or the copolymerization between $\mathrm{CO}_{2}$ and propylene oxide. ${ }^{[33,34,35]}$ In the first case, indeed, Lu and his group reported the high efficiency of the association $\mathrm{Co}$ (III)-salen/quaternary ammonium halide as catalyst to promote the coupling reaction of $\mathrm{CO}_{2}$ and racemic epoxides through a kinetic resolution, at a low $\mathrm{CO}_{2}$ pressure. Both the nature of the axial ligand and of the ammonium salt had great effect on the enantiomeric purity and reaction rate. By using $\mathrm{Co}(\mathrm{III})(\mathrm{OTs})-\mathrm{Salen} / n-\mathrm{Bu}_{4} \mathrm{NCl}$, the best selectivity factor of 9 was achieved, delivering the propylene

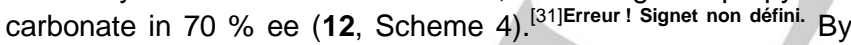
optimizing this initial system, Berkessel et al. afforded this compound with an improved selectivity factor of 19 (up to $83 \%$ ee and $40 \%$ yield), via a cobalt trifluoroacetyl complex and bis(triphenylphos-phoranylidene)ammonium fluoride $\left(\mathrm{PPN}^{+} \mathrm{F}^{-}\right)$as dual catalysts (13, Scheme 4). ${ }^{[32]}$

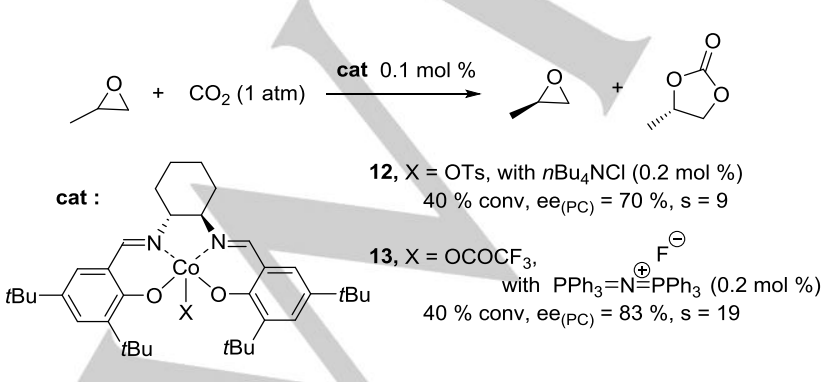

Scheme 4. Resolution of racemic propylene oxide by coupling with $\mathrm{CO}_{2}$ towards enantioenriched propylene carbonate.
As pendant reaction, Coates and coworkers described a catalytic system minimizing the cyclic product to be produced, to favor the formation of the corresponding polycarbonate resulting from the alternating copolymerization of $\mathrm{CO}_{2}$, as attractive $\mathrm{C}_{1}$ feedstock, with epoxides. ${ }^{[33]}$ By using a $\mathrm{Co}(\mathrm{III})(\mathrm{OAc})$-salen complex, the polymerization occurred with a high selectivity towards the formation of an alternate polycarbonate with $95 \%$ carbonate linkages and a narrow polydispersity, at 55 bar $\mathrm{CO}_{2}$, without the need of additives. By adding a Lewis base to this system (for instance DMAQ, N'N-dimethylaminoquinoline), ${ }^{[34]}$ it was possible to perform the same transformation at a lower $\mathrm{CO}_{2}$ pressure. Improvements were further achieved by the design of Co(III)-salen catalysts bearing ammonium substituents on the ligand structure; when used at 10 bar $\mathrm{CO}_{2}$ and room temperature, an iso-enriched stereogradient poly(propylene carbonate) was obtained, formed at one end from the more reactive enantiomer of propylene oxide until $50 \%$ conversion, and then incorporation of the less reactive enantiomer. ${ }^{[35]}$

\section{Cobalt-salen complexes, intimately associated with epoxides reactivity}

This last transformation utilizing epoxides is based on the most renowned reactivity of Co-salen complexes, i.e. their ability to perform the efficient kinetic resolution of terminal epoxides with water. ${ }^{[5]}$ Jacobsen and his group discovered indeed that the solvent-free reaction of racemic propylene oxide with water $(0.55$ equivalent) in the presence of the classical $\mathrm{Co}(\mathrm{OAc})$-salen catalyst led to the unreacted epoxide and propylene glycol, both highly valuable compounds, in quantitative yield and excellent enantiomeric purity. Of great interest, this system displays an extraordinary substrate generality delivering a practical and unexpensive access to various enantiopure terminal epoxides, as useful starting blocks for the straightforward synthesis of chiral drugs. ${ }^{[36]}$ Jacobsen reported that this discovery resulted from an observation made during the study of the asymmetric ring opening (ARO) of meso-epoxides. ${ }^{[37]}$ Searching indeed for the use of other nucleophiles in these reactions, his group described the efficient use of $\mathrm{Co}$ (III)-salen derivatives together with carboxylic acids. ${ }^{[38]}$ When these reactions conditions were applied to the kinetic resolution of terminal epoxides, using benzoic acid as the nucleophile, they identified the formation of highly enantioenriched 1,2-diols as byproducts and proved their formation to result from the kinetic resolution with fortuitous water in the reaction mixture. Kinetic studies indicated that the reaction occurred through bimetallic activation, as a secondorder dependence on the concentration of the $\mathrm{Co}$ (III)-salen catalyst was determined. ${ }^{[7]}$ Furthermore, the nature of the metal counterion proved of utmost importance in the reaction mechanism, directly responsible for a catalyst partitioning between two species that react together in the rate-determining step, with the best reactivity and selectivity achieved for a perfect balance between the concentration of a $[\mathrm{Co}-\mathrm{OH}]$ species (for the activation of the nucleophile) and a [Co-X] species (for the activation of the electrophile). Therefore, subsequent studies focused on two points; first, attempting an ideal placement of the 
Co-salen complexes, for instance through precise immobilization, to favor at best bimetallic activation, and second, aiming for control the quantity of the two active sites. We explored both directions, ${ }^{[39]}$ which will now be discussed, supported by advances from other groups.

As soon as 1999, Jacobsen and his group described the immobilisation of specifically functionalized Co-salen complexes on organic resins (hydroxymethyl polystyrene) or inorganic supports (silica) via covalent immobilization ${ }^{[40]}$ and reported consequently the easy recovery and purification of the targeted products. The comparison of the hydrolyses kinetic profiles obtained from silica-supported catalysts with various loadings confirmed a bimetallic activation, with the reaction rate increasing with the catalytic loading. The very high stability of the procedure applied to the kinetic resolution of epoxides with phenols allowed its application in parallel libraries from a large group of racemic epoxides and a variety of phenols, to provide numerous 1-aryloxy-2-alcohols, as valuable compounds, in high yield and enantiopurity. ${ }^{[41]}$ These immobilized catalysts have also been placed in a fixed-bed reactor and efficiently adapted to a continuous flow process. ${ }^{[40,42]}$

The following studies concerning Co-salen complexes immobilization aimed specifically at targeting the precise localization of the active sites, to best promote their proximity for optimized bimetallic activation. In this context, Weck and his group designed supported-complexes on polystyrene beads, via oligo(ethylene glycol) ${ }^{[43]}$ or dendron linkers ${ }^{[44]}$ and systematically studied different lengths and catalysts density to deliver efficient and recyclable species that outperformed the activity obtained with the monometallic Jacobsen-type catalysts, thanks to the close proximity of two catalytic sites to each other. We proposed to target the active sites confinement thanks to macromolecular engineering, and more precisely by ATRP (Atom Transfer Radical Polymerization) in solution for the copolymerization of styrene and styrenyl-derived salen monomers. ${ }^{[45]}$ Searching for a precise control of the polymerization and of the level of ligand incorporation, we discovered that the polymer growth was only controlled at low salen comonomer loading. In those conditions, first-order kinetics, linear increase of $\mathrm{Mn}$ versus time and monomodal narrow molar mass distributions were satisfactorily achieved. For copolymers with higher incorporated salen comonomer, control of the reaction progressively disappeared with increasing dispersities; nevertheless, and in spite of the loss of polymerization control, the highest $(50 \%)$ salen incorporation yielded the best catalytic results. Such a strategy was also investigated by the group of Jones, for preparing polystyrene brushes containing cobalt-salen complexes grafted on silica. ${ }^{[46]}$ However, the expected controlled character of ATRP in terms of well-defined number average molar mass, distribution of molar mass and kinetics were not definitely completed. Some success was also achieved to prepare catalysts for enhanced reactivity through direct polymerization of a suitably modified salen derivative to provoke cross-linkage ${ }^{[47]}$ and with the use of a dendritic catalyst with the active sites placed at the periphery for improved cooperativity. ${ }^{[48]}$

The group of Jacobsen further pioneered another way to control the precise location of the active sites, with regard each one to the other, through modification of the salen ligand for its insertion in chiral macrocycles. ${ }^{[49]}$ They prepared pimelate-linked oligomeric $\mathrm{Co}(\mathrm{II})$-salen complexes that were oxidized in air with various Brønsted acids to provide the corresponding active oligomers (Scheme 5).

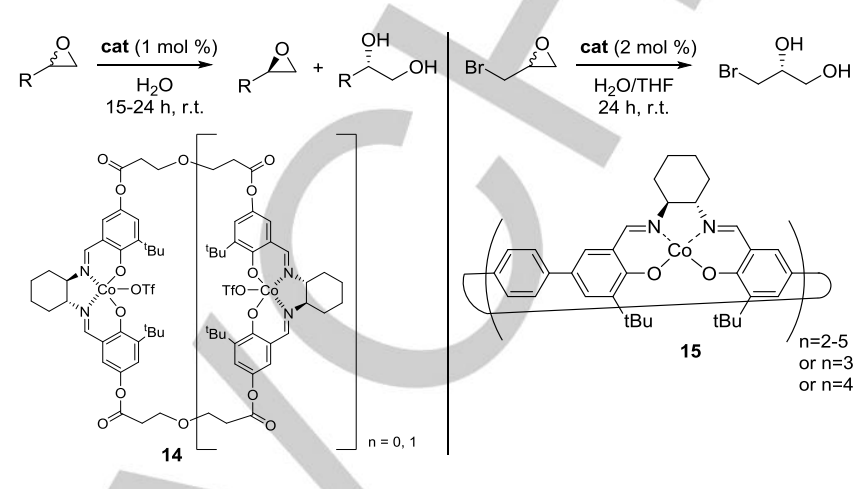

Scheme 5. HKR of terminal epoxides with macrocyclic, oligomeric Co-salen complexes.

These cyclic complexes confirmed their ability to realize the HKR with higher efficiency than the corresponding monomers, especially for the ARO of challenging substrates such as mesoepoxides and oxetanes. ${ }^{[49 c, 50]}$ The authors assumed that this resulted from the optimized cooperative reactions within the oligomers, due to their flexibility allowing an ideal placement of two active sites for bimetallic activation through an head-to-tail arrangement of the salen units. The Co(II)-oligomers, obtained in an original way via ring-opening metathesis polymerization of cyclooctene-modified salen monomers and already presented as catalysts for the Henry reaction (Figure 2) were tested as catalysts for the HKR of terminal epoxides, after activation under aerobic and acid conditions: ${ }^{[51]}$ they also demonstrated an enhanced activity due to efficient bimetallic activation, thanks to their flexibility and the high concentration of the cobalt active sites, provided the use of large ring-size macrocyclic catalysts. ${ }^{[52]}$

We reported the synthesis of new chiral salen-containing macrocycles through straightforward polycondensation reactions between enantiopure diamines and aryl-linked disalicylaldehyde derivatives (7 in Scheme 3 or 15 in Scheme 5). ${ }^{[26]}$ These derivatives have been used after coordination with cobalt salts and oxidation in the dynamic hydrolytic resolution of epibromohydrin, either as a mixture of oligomers or in their pure form. ${ }^{[53]}$ Indeed, and according to the synthetic reaction conditions, namely the concentration, the macrocyclic calixsalens were obtained as a mixture or as pure trimer or tetramer complexes after silicagel purification. In this case again, the largest isolated macrocycle, i.e. the tetramer calix-salen cobalt complex, proved to be the most active and selective catalyst of the series, allowing an optimal conformation to deliver the expected diol with both high enantioselectivity and yield, thanks to dynamic kinetic resolution. Moreover, since the catalysts were insoluble in the reaction medium and acted as heterogeneous enantioselective catalysts, they were easily recovered from the 
reaction mixture by simple filtration. Remarkably, these catalysts could be reused in other runs to produce the targeted diol with steady enantioselectivity but decreasing yield (up to 6 runs). As already reported for Co-OAc complexes delivering gradually non-nucleophilic $\mathrm{Co}-\mathrm{OH}$ species, a reactivation step with acetic acid was needed to recover a high activity.

Chemists demonstrated great creativity to both try to favour this sought-after metal biactivation, but also to promote efficient recycling of the catalytic species. Jacobsen and his group modified salen complexes by thiol functionalities able to selfassemble as monolayers on gold colloids (16, Figure 4) showing significant rate-acceleration compared to the catalysis driven by the monomeric analogues. ${ }^{[54]}$ The group of Weck reported the judicious preparation of micelles from amphiphilic poly(2oxazoline) triblock copolymers containing salen ligands, after photo-cross-linking and subsequent metalation. ${ }^{[5]}$ These catalysts, as nano-reactors, demonstrated a high efficiency and a substrate selectivity based on hydrophobicity; they were recovered and successfully reused by passing the reaction solution through an ultrafiltration membrane. We were able to covalently attached eight cobalt-salen complexes to a calix[8]arene platform through a flexible linker by a procedure employing click chemistry (17, Scheme 4$).^{[56]}$ In this case again, efficient cooperativity was demonstrated compared to the monomeric analogue and due to the insoluble character of the immobilized catalyst, it was easily recovered and reused. Furthermore, a very low metal leaching inside the crude after filtration $(\approx 1 \mathrm{ppm})$ was obtained, thus as valuable immobilization strategy for the preparation of pharmaceutical intermediates.

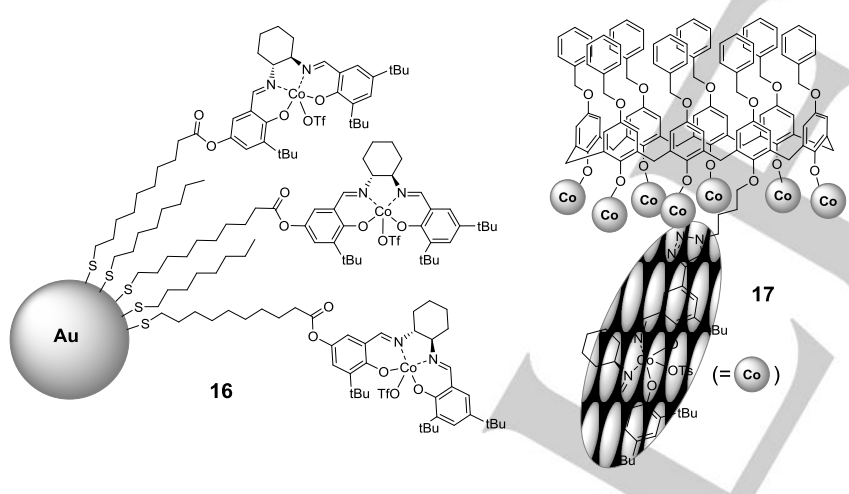

Figure 4. Immobilization procedures for the HKR of terminal epoxides.

As other examples, which will not make it possible to achieve exhaustiveness, worth mentioning is the successful heterogenization of Co-salen complexes entrapped into a membrane ${ }^{[57]}$ inserted into the mesoporous cage of SBA-16 following a "ship in a bottle" procedure, ${ }^{[58]}$ or through immobilization by electrostatic linkage. ${ }^{[59]}$ Even if in these cases successful recycling of the catalysts was achieved, it was inevitably conditioned to a catalyst reactivation step under acidic conditions, to maintain the activation of the electrophile by the catalyst.

In an attempt to control both the stability of the active sites and also the possibility to recycle and reuse the catalytic material without the need of a reactivation step, we investigated the preparation of enantiopure thiophene-salen ligands. We reported then the synthesis of the corresponding organic conducting polymers by anodic oxidation of their chromium, copper, nickel and cobalt complexes. ${ }^{[60]}$ These polymers showed a high chemical and electrochemical stability allowing their possible use as asymmetric catalysts. They were furthermore recovered as insoluble species in common organic solvents and consequently involved as easily filtrable, heterogeneous catalysts. In the context of HKR and considering the detailed mechanistic studies, ${ }^{[7] E r r e u r ! ~ S i g n e t ~ n o n ~ d e ́ f i n i . ~ t h e ~ p o l y m e r i z a t i o n ~}$ conditions were fine-tuned to optimize the structure of the insoluble polymers for catalytic activity, with the aim to reach cobalt active sites containing a balanced amount of both nucleophilic and non-nucleophilic axial ligands (see 18, in Scheme 6$).{ }^{[61]}$ This could be delightfully achieved from the onepot oxidation/electrochemical polymerization of an inactive $\mathrm{Co}(\mathrm{II})$-salen complex, in the presence of $n \mathrm{Bu}_{4} \mathrm{NBF}_{4}$ in a $\mathrm{DCM} / \mathrm{CH}_{3} \mathrm{COOH}$ mixture, to afford a copolymer that contained both $\mathrm{Co}(\mathrm{III})-\mathrm{BF}_{4}$ and $\mathrm{Co}$ (III)-OAc units. The resulting catalyst was highly efficient in terms of activity and enantioselectivity for the dynamic kinetic resolution (DKR) of epibromohydrin and the HKR of various terminal epoxides. As far as we know, polymer 18 was the first heterogeneous analogue of Jacobsen's Cosalen complex that was efficiently reused more than ten times without the need for an extra reactivation step.

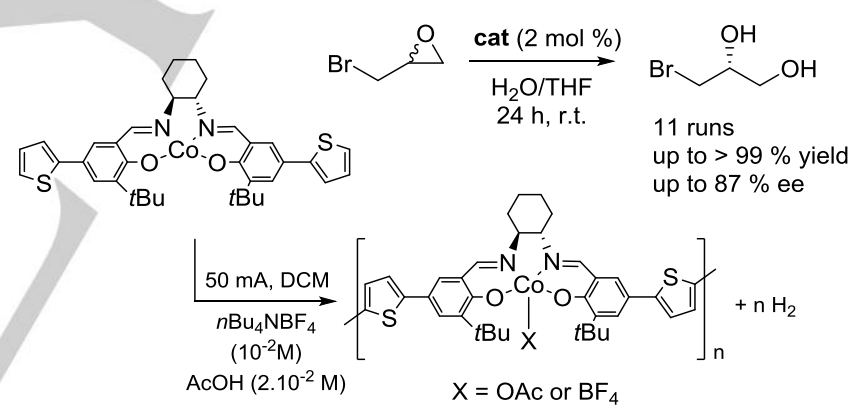

18

Scheme 6. Electrochemical polymerization of a Co(II)-thiophene-salen complex and use in heterogeneous DKR of epibromohydrin.

We further investigated the chemical-promoted oxidative polymerization of the same thiophene modified-cobalt salen complexes. ${ }^{[62]}$ In this case, we have purposefully prepared a $\mathrm{Co}(\mathrm{III})-\mathrm{BF}_{4}$ salen complex through oxidation of the $\mathrm{Co}$ (II) precursor with ferrocenium tetrafluoroborate; copolymerization occurred then by mixing an equimolar amount of both monomers, possessing $\mathrm{Co}(\mathrm{III})-\mathrm{OAc}$ or $\mathrm{Co}(\mathrm{III})-\mathrm{BF}_{4}$ sites, to deliver an insoluble powder in very high yield by oxidation with iron chloride. To determine the extent of applications of 19 (Scheme 7), this insoluble catalyst was used in a batch procedure for promoting successively the hydrolytic kinetic resolution of different terminal epoxides, by changing the structure of the substrate at each reuse of the polymer. A first run was hence devoted to the HKR of epibromohydrin yielding the expected results. The recovered 
catalyst was then engaged in the transformation of 2phenoxymethyloxirane, then 2-allyloxymethyloxirane was hydrolyzed, followed by 2-phenyloxirane and the last run was assigned again to the hydrolysis of epibromohydrin. Detailed kinetic studies were realized for the first run and the fifth reuse of 19 and no obvious difference was observed. We also proved that no metal leaching occurred; this undoubtedly demonstrated the stability of this easily prepared polymer in the HKR.

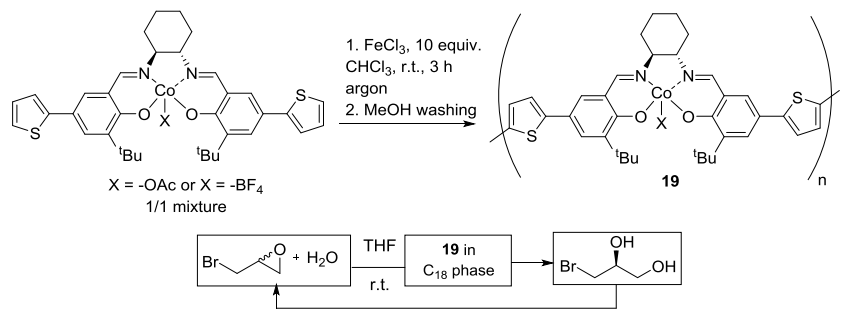

Scheme 7. Chemical co-polymerization of $\mathrm{Co}$ (III)-thiophene-salen complexes and use in a fixed-bed procedure.

We further experienced the immobilization of the prepared insoluble catalyst in a fixed-bed reactor to facilitate, at best, the recycling technique by a more efficient purification procedure and catalyst reuse. 19 was immobilized in a short HPLC-type pre-column through mixing with an octadecyl $\mathrm{C} 18$ carbon chainbonded silica in a reversed phase mode (Scheme 7), to enable the release of the diol resulting from the DKR, thus preventing fast reactor saturation. In this home-made flow reactor, DKR of epibromohydrin was realized under diluted conditions, leading to excellent results proving the stability of the polymeric catalyst, possessing both nucleophilic and non-nucleophilic active sites, the latter not being able to deactivate.

Since catalyst deactivation is due to irreversible hydrolysis of the $\mathrm{Co}$ (III)-OAc complex to a $\mathrm{Co}$ (III)-OH species in the HKR, we envisaged another solution to afford more stable bimetallic catalysts; we proposed that a combination of two different thiophene modified salen metal complexes, as heterobimetallic systems, could lead to an efficient catalyst duo. By adding other salen metal complexes supposed to be involved only as epoxide activators to a $\mathrm{Co}$ (III)-OAc complex, we discovered indeed that the concomitant use of a $\mathrm{Mn}(\mathrm{III})-\mathrm{Cl}$ salen complex led to enhanced selectivity in the DKR of epibromohydrin (Figure 5). ${ }^{[63]}$ This enrichment only occurred if both metallic complexes resulted exclusively from ligands possessing the same configuration. We propose that the bimetallic arrangement necessary for obtaining high enantioselectivities, i.e. the "headto-tail" organization, ${ }^{[64]}$ is only feasible under these conditions. Even if this catalytic system is clearly not competing with previously described very efficient complexes in this reaction, it allows gaining some insight into the mechanism. Kinetic studies indicated that only one Co(III)-salen complex was involved in the rate-determining step, which supported a heterobimetallic highly enantioselective pathway based on the crucial existence of in situ generated $\mathrm{Co}$ (III)-OH species, previously postulated in the literature. The beneficial effect of the presence of additional Mncomplexes was ascribed to the inhibition of the alternative less enantioselective monometallic reaction pathway by epoxide activation, only possible with the same ligand configuration, to yield the optimized shape in the selectivity-determining transition state for the formation of the product. Applied in the HKR of other terminal epoxides, the heterobimetallic dual catalyst system exhibited also greatly enhanced enantioselectivities (Figure 5).

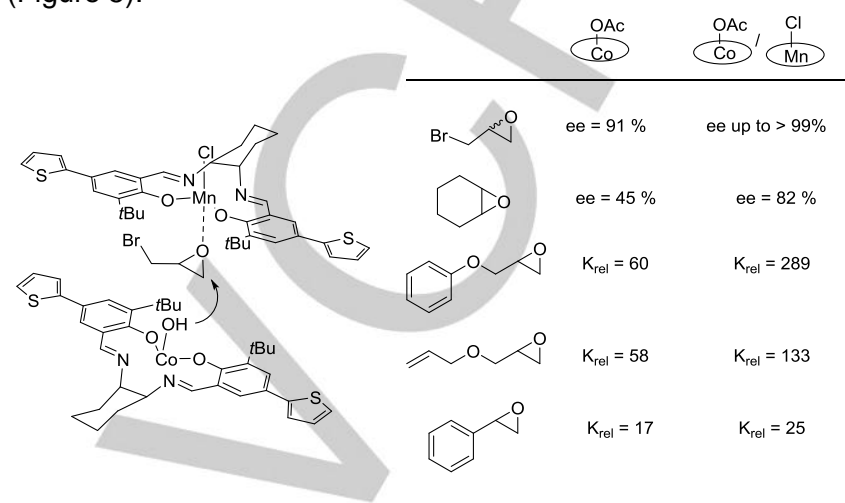

Figure 5. Enantioselective hydrolysis of epoxides with a heterobimetallic dualcatalyst system.

We were pleased to show that this heterobimetallic system was not only efficient in homogeneous catalysis, but could be also applied to heterogeneous conditions. As previously reported, Erreur! Signet non défini. we prepared Co-salen complexes embedded into macrocyclic calixarenic-like structures, and their $\mathrm{Mn}-\mathrm{Cl}$ analogues were accordingly synthesised in high yields. ${ }^{[65]}$ Both complexes were engaged together as heterogeneous catalysts to promote the DKR of epibromohydrin. A phenomenon similar to that observed under homogeneous conditions occurred, i.e. the mixing of both homometallic oligomeric salen complexes, using an equimolar combination of cobalt and manganese calixsalen-derivatives, led to better results than those obtained by using the Co-containing macrocycle alone (Scheme 8). Furthermore, as insoluble species, the catalytic mixture was easily recovered by simple filtration and successfully reengaged in subsequent catalytic runs.
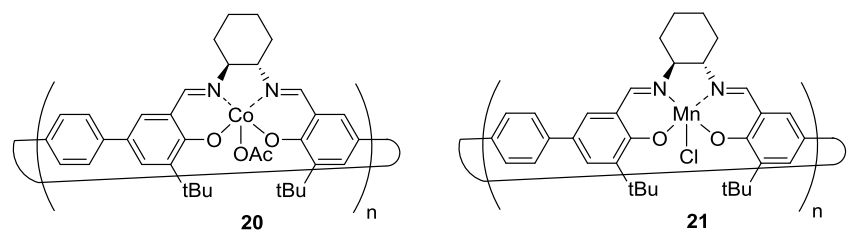

\begin{tabular}{|c|c|c|c|c|c|}
\hline & & \multicolumn{2}{|c|}{$20(2 \mathrm{~mol} \%)$} & \multicolumn{2}{|c|}{$20(1 \mathrm{~mol} \%)+21(1 \mathrm{~mol} \%)$} \\
\hline & Run & conv $(\%)$ & ee $(\%)$ & conv (\%) & ee $(\%)$ \\
\hline cat & 1 & $>99$ & 88 & 97 & 92 \\
\hline $\mathrm{H}_{2} \mathrm{O} / \mathrm{THF}$ & 2 & 88 & 89 & 97 & 90 \\
\hline 24 h, r.t. & 3 & 83 & 93 & 97 & 90 \\
\hline & 4 & 68 & 91 & 97 & 90 \\
\hline & 5 & $85^{\star}$ & $89^{*}$ & 97 & 90 \\
\hline & 6 & \multirow{3}{*}{\multicolumn{2}{|c|}{$\begin{array}{l}\text { *after } \mathrm{AcOH} \\
\text { reactivation }\end{array}$}} & 82 & 90 \\
\hline & 7 & & & 83 & 86 \\
\hline & 8 & & & 83 & 82 \\
\hline
\end{tabular}

Scheme 8. DKR of epibromohydrin under heterogeneous conditions with a mixture of homometallic macrocyclic Co-salen complexes. 
Whereas cobalt reactivation with acetic acid was mandatory to recover the activity of catalyst $\mathbf{2 0}$ after the fourth reuse, this was unnecessary for the dual system $(20+21)$ which maintained its activity for about eight runs. Studying the more challenging hydrolysis of meso-epoxides, we also noticed that this enhanced reactivity for the dual-system occurred only if both salen derivatives possessed the same configuration at the stereogenic centres, a match effect thus interestingly also valuable between two heterogenized Co- and Mn-species.

\section{Conclusion and outlook}

Since their discovery, enantiopure cobalt-salen complexes have been used to catalyze a wide variety of asymmetric reactions and it is very interesting to still read new developments for their application. Research and discoveries concerning the understanding of their mechanism of action, in particular for the hydrolysis of epoxides, have inspired many works to promote the bimetallic cooperativity which resulted from it. In general, when catalysts immobilization on various supports is studied for their easy recovery for instance, all efforts are drawn towards the development of grafting links that do not modify the active site, to minimize the potential effect of the support; furthermore, their efficient dilution is desired to prevent mutual inhibition, targeting thus often compartmentalization of the catalysts. It is interesting to note that in the case of cobalt-salen complexes, a proximity, on the contrary, was sought to promote their optimal reactivity. In this context, further particularly original developments have been published in the very last years. Considering on one hand homogeneous catalysis, the use of non-covalent interactions of donor-acceptor type was used for preparing Co-salen dimers. ${ }^{[6]}$ Although formation of charge transfer-complexes was used for numerous applications, it was rarely applied in asymmetric catalysis but in two examples, one arising from our group, ${ }^{[67]}$ for the supramolecular assembly of ligands to form bidentate complexes. Here, Liang and Liu's group prepared symmetrical or unsymmetrical Co-salen derivatives bearing electron-donor and/or electron-acceptor substituents, as naphthalenediimide or pyrene groups. Thanks to NMR and UV-vis absorption spectroscopy studies, their association by donor-acceptor interactions was proved, leading to higher catalytic efficiency in the asymmetric hydrolytic ring opening of various epoxides, as a proof for an efficient driving force towards cooperative catalysis. On the other hand, and considering heterogeneous catalysis, salen derivatives have been used as chiral organometallic struts to be assembled in metal organic frameworks (MOFs), as enantioselective and recyclable catalysts. The crystallinity of these nanoporous networks allows indeed for the direct knowledge of their structure and thus the control of the active site's location and their environment, which is a major asset to optimize their reactivity. To mention a few selected examples related to the reactivity of cobalt complexes, Liu, Cui and collaborators prepared multivariate MOFs containing up to three salen complexes coordinated to different metals, as interpenetrated networks featuring multiple and cooperative active sites in close proximity. As insoluble species, such Co-and Mn-salen containing MOFs revealed as efficient recyclable catalysts and further allowed tandem catalytic reactions to be efficiently performed with alkenes epoxidation followed by subsequent epoxide hydrolysis with the bimetallic complexes. ${ }^{\left[{ }^{[8]}\right.}$ Crystalline covalent organic frameworks (COFs), incorporating metallo salen units, have been very recently reported, in which salen moieties are no more connected via coordination but via covalent bonds by formation of multiple imine linkages with tritopic salicylaldehyde monomers. In this context the same group prepared covalent networks with multiple heterometallic active centers also able to promote the tandem catalysis, showing in addition to their high reactivity their easy recovery and reuse, maintaining their performance for five runs. ${ }^{[69]}$

The synthesis of such elaborated networks made it possible to further enhance the extraordinary scope of application of Cosalen complexes in other asymmetric reactions of tandem type. Furthermore, cobalt-salen complexes have also been reported to promote new transformations, when intimately associated to a chiral organocatalyst, either as a bifunctional species. ${ }^{[70]}$ or as two distinct catalysts. ${ }^{[71]}$ These results are particularly appealing and are promises to wide developments especially in the field of asymmetric heterogeneous catalysis. In fact, the immobilization on a support of two different catalytic species can, at will, promote either their proximity or their compartmentalization; there are still many grafting routes to explore, whether they are covalent or not. On the other hand, and unlike the preparation of bifunctional catalysts, the immobilization of two independent species will make it possible to vary their respective ratio, to optimize their importance in the catalytic cycle much more quickly. We are convinced that those co-salen complexes are excellent objects of study to refine these different immobilization pathways, thanks to their multiple reactivity. Such work is still currently underway in our group.

\section{Acknowledgements}

I am sincerely very grateful to all of my collaborators, especially Drs M. Mellah and N. Jaber, and to all the graduate students who have helped me explore the chemistry of salen complexes. Université Paris Saclay, CNRS and Charm3At LabEx (ANR-11LABEX-0039) are acknowledged for financial support.

Keywords: asymmetric catalysis • salen complexes • epoxides opening $\cdot$ cooperativity $\cdot$ recycling

[1] a) W. S. Knowles, Angew. Chem. Int. Ed., 2002, 41, 1998-2007; b) R Noyori, Angew. Chem. Int. Ed., 2002, 41, 2008-2022; c) K. B. Sharpless, Angew. Chem. Int. Ed., 2002, 41, 2024-2032.

[2] P Pfeiffer, E. Breith, E. Lübbe, T. Tsumaki, Justus Liebigs Ann. Chem. 1933, 503, 84-130.

[3] E. N. Jacobsen, W. Zhang, A. R. Muci, J. R. Ecker, L. Deng, J. Am. Chem. Soc. 1991, 113, 7063-7064.

[4] a) P. G. Cozzi, Chem. Soc. Rev. 2004, 33, 410-421; b) S. Shaw, J. D. White, Chem. Rev. 2019, 119, 9381-9426.

[5] M. Tokunaga, J. F. Larrow, F. Kakiuchi, E. N. Jacobsen, Science 1997, 277, 936-938. 
[6] L. Aouni, K. E. Hemberger, S. Jasmin, H. Kabir, J. F. Larrow, I. Le-Fur, P. Morel, T. Schlama, In Asymmetric Catalysis on Industrial Scale: Challenges, Approaches and Solutions, 1st Ed., (Eds.: H.-U. Blaser, E. Schmidt), Wiley-VCH, Weinheim, 2004, pp.165-199.

[7] L. P. C. Nielsen, C. P. Stevenson, D. G. Blackmond, E. N. Jacobsen, J. Am. Chem. Soc. 2004, 126, 1360-1362.

[8] a) L. Canali, D. C. Sherrington, Chem. Soc. Rev. 1999, 28, 85-93; b) C. Baleizão, H. Garcia, Chem. Rev. 2006, 106, 3987-4043; c) A. Zulauf, M. Mellah, X. Hong, E. Schulz, Dalton Trans. 2010, 39, 6911-6935; d) M. Abd El Sater, N. Jaber, E. Schulz, ChemCatChem 2019, 11, 3662-3687.

[9] W. Kahlen, H. H. Wagner, W. F. Hölderich, Catal. Lett. 1998, 54, 85-89.

[10] T. Uchida, T. Katsuki, Tet. Lett. 2001, 42, 6911-6914.

[11] T. Kobayashi, T. Shimura, Y. Kurita, Y. Katsumata, S. Kezuka, Tet. Lett. 2014, 55, 2818-2821.

[12] T. J. R. Achard, Y. N. Belokon', M. Ilyin, M. Moskalenko, M. North, F. Pizzato, Tet. Lett. 2007, 48, 2965-2969.

[13] T. Fukuda, T. Katsuki, Tetrahedron 1997, 53, 7201-7208.

[14] T. Uchida, T. Katsuki, Synthesis 2006, 1715-1723.

[15] T. Niimi, T. Uchida, R. Irie, T. Katsuki, Tet. Lett. 2000, 41, 3647-3651.

[16] T. Niimi, T. Uchida, R. Irie, T. Katsuki, Adv. Synth. Catal. 2001, 343, 7988.

[17] T. Uchida, B. Saha, T. Katsuki, Tet. Lett. 2001, 42, 2521-2524.

[18] J. D. White, S. Shaw, Org. Lett. 2014, 16, 3880-3883.

[19] a) Y. Huang, T. Iwama, V. H. Rawal, J. Am. Chem. Soc. 2002, 124 5950-5951; b) J. D. McGilvra, V. H. Rawal, Synlett 2004, 2440-2442.

[20] G. E. Hutson, A. H. Dave, V. H. Rawal, Org. Lett. 2007, 9, 3869-3872.

[21] Y. N. Belokon, J. Fuentes, M. North, J. W. Steed, Tetrahedron 2004, 60, 3191-3204.

[22] Z. Dong, X. Liu, J. Feng, M. Wang, L. Lin, X. Feng, Eur. J. Org. Chem. 2011, 137-142.

[23] Y. Kogami, T. Nakajima, T. Ikeno, T. Yamada, Synthesis 2004, $1947-$ 1950

[24] J. Park, K. Lang, K. A. Abboud, S. Hong, J. Am. Chem. Soc. 2008, 130 , 16484-16485.

[25] M. Holbach, X. Zheng, C. Burd, C. W. Jones, M. Weck, J. Org. Chem. 2006, 71, 2903-2906.

[26] F. Ibrahim, H. Nasrallah, X. Hong, M. Mellah, A. Hachem, G. Ibrahim, N. jaber, E. Schulz, Tetrahedron 2012, 68, 9954-9961.

[27] F. Ibrahim, N. Jaber, V. Guérineau, A. Hachem, G. Ibrahim, M. Mellah, E. Schulz, Tetrahedron: Asymm. 2013, 24, 1395-1401.

[28] Y.-L. Wei, K.-F. Yang, F. Li, Z.-J. Zheng, Z. Xu, L.-W. Xu, RSC Adv. 2014, 4, 37859-37867.

[29] J. Dimroth, M. Weck, RSC Adv. 2015, 5, 29108-29113.

[30] D. Taura, S. Hioki, J. Tanabe, N. Ousaka, E. Yashima, ACS Catal. 2016, 6, 4685-4689.

[31] X.-B. Lu, B. Liang, Y.-J. Zhang, Y.-Z. Tian, Y.-M. Wang, C.-X. Bai, H. Wang, R. Zhang, J. Am. Chem. Soc. 2004, 126, 3732-3733.

[32] A. Berkessel, M. Brandenburg, Org. Lett. 2006, 8, 4401-4404.

[33] Z. Qin, C. M. Thomas, S. Lee, G. W. Coates, Angew. Chem. Int. Ed. 2003, 42, 5484-5487

[34] R. L. Paddock, S. T. Nguyen, Macromol. 2005, 38, 6251-6253.

[35] K. Nakano, S. Hashimoto, M. Nakamura, T. Kamada, K. Nozaki, Angew. Chem. Int. Ed. 2011, 50, 4868-4871.

[36] a) S. V. Narina, A. Sudalai, Tetrahedron 2007, 63, 3026-3030; b) R. B. Kawthekar, G.-J. Kim, Helv. Chim. Acta 2008, 91, 317-332; c) M. Muthukrishnan, M. Mujahid, M. Sasikumar, P. Mujumdar, Tetrahedron Asymmetry 2011, 22, 1353-1357; d) M. Kumar, R. I. Kureshy, A. K. Shah, A. Das, N.-I H. Khan, S. H. R. Abdi, H. C. Bajaj, J. Org. Chem. 2013, 78, 9076-9084; e) T. Roy, S. Barik, M. Kumar, R. I. Kureshy, B. Ganguly, N.-I H. Khan, S. H. R. Abdi, H. C. Bajaj, Catal. Sci. Technol. 2014, 4, 3899-3908; f) R. Tak, M. Kumar, T. Menapara, N. Gupta, R. I. Kureshy, N-I H. Khan, E. Suresh, Adv. Synth. Catal. 2017, 359, 39904001.

[37] E. N. Jacobsen, Acc. Chem. Res. 2000, 33, 421-431.
[38] E. N. Jacobsen, F. Kakiuchi, R. G. Konsler, J. F. Larrow, M. Tokunaga, Tet. Lett. 1997, 38, 773-776.

[39] H. Dandachi, X. Hong, F. Ibrahim, H. Nasrallah, A. Zulauf, N. Jaber, M. Mellah, E. Schulz, Vietnam J. Chem. 2020, 58, 29-39.

[40] D. A. Annis, E. N. Jacobsen, J. Am. Chem. Soc. 1999, 121, 4147-4154

[41] S. Peukert, E. N. Jacobsen, Org. Lett. 1999, 1, 1245-1248.

[42] W. Solodenko, G. Jas, U. Kunz, A. Kirschning, Synthesis 2007, 583 589.

[43] X. Zheng, C. W. Jones, M. Weck, Adv. Synth. Catal. 2008, 350, 255261.

[44] P. Goyal, X. Zheng, M. Weck, Adv. Synth. Catal. 2008, 350, 1816-1822.

[45] N. Zidelmal, N. Aubry-Barroca, B. Lepoittevin, M. Mellah, L. Costa, F. Ozanam, A.-C. Gouget-Laemmel, E. Schulz, P. Roger, Polymer 2018, 135, 261-270.

[46] C. S. Gill, K. Venkatasubbaiah, N. T. S. Phan, M. Weck, C. W. Jones, Chem. Eur. J. 2008, 14, 7306-7313.

[47] Y. Song, H. Chen, X. Hu, C. Bai, Z. Zheng, Tet. Lett. 2003, 44, 70817085

[48] R. Breinbauer, E. N. Jacobsen, Angew. Chem. Int. Ed. 2000, 39, 3604 3607

[49] a) J. M. Ready, E. N. Jacobsen, J. Am.Chem. Soc. 2001, 123, 2687 2688; b) J. M. Ready, E. N. Jacobsen, Angew. Chem. Int. Ed. 2002, 41 1374-1377; c) D. E. White, P. M. Tadross, Z. Lu, E. N. Jacobsen, Tetrahedron 2014, 70, 4165-4180.

[50] R. N. Loy, E. N. Jacobsen, J. Am.Chem. Soc. 2009, 131, 2786-2787.

[51] X. Zheng, C. W. Jones, M. Weck, J. Am. Chem. Soc. 2007, 129, 1105 1112

[52] Y. Liu, J. Rawlston, A. T. Swann, T. Takatani, C. D. Sherrill, P. J. Ludovice, M. Weck, Chem. Sci. 2011, 2, 429-438.

[53] H. Dandachi, H. Nasrallah, F. Ibrahim, X. Hong, M. Mellah, N. Jaber, E. Schulz, J. Mol. Cat. A: Chem. 2014, 395, 457-462.

[54] T. Belser, E. N. Jacobsen, Adv. Synth. Catal. 2008, 350, 967-971.

[55] Y. Liu, Y. Wang, Y. Wang, J. Lu, V. Piñon, M. Weck, J. Am.Chem. Soc. 2011, 133, 14260-14263.

[56] I. Abdellah, C. Martini, A. Dos Santos, D. Dragoe, V. Guérineau, V. Huc E. Schulz, ChemCatChem 2018, 10, 4761-4767.

[57] S.-D. Choi, G.-J. Kim, Catal. Lett. 2004, 92, 35-40.

[58] H. Yang, L. Zhang, W. Su, Q. Yang, C. Li, J. Catal. 2007, 248, 204-212.

[59] Y.-S. Kim, X.-F. Guo, G.-J. Kim, Chem. Commun. 2009, 4296-4298.

[60] a) A. Voituriez, M. Mellah, E. Schulz, Synth. Met. 2006, 156, 166-175; b) A. Zulauf, X. Hong, F. Brisset, E. Schulz, M. Mellah, New J. Chem. 2012, 36, 1399-140.

[61] X. Hong, M. Mellah, F. Bordier, R. Guillot, E. Schulz, ChemCatChem 2012, 4, 1115-1121.

[62] X. Hong, L. Billon, M. Mellah, E. Schulz, Cat. Sci. Technol. 2013, 3, 723-729.

[63] X. Hong, M. Mellah, E. Schulz, Cat. Sci. Technol. 2014, 4, 2608-2617.

[64] R. G. Konsler, J. Karl, E. N. Jacobsen, J. Am. Chem. Soc. 1998, 120, 10780-10781.

[65] H. Dandachi, E. Zaborova, E. Kolodziej, O. R. P. David, J. Hannedouche, M. Mellah, N. Jaber, E. Schulz, Tetrahedron: Asymm. 2016, 27, 246-253.

[66] a) D. R. Blechshmidt, M. D. Woodhouse, S. Inagaki, M. Whitfield, A Ogunsanya, A. Yoder, D. Lilly, E. W. Heim, L. N. Soucie, J. Liang, Y. Liu, Org. Biomol. Chem. 2019, 17, 172-180; b) J. Liang, L. N. Soucie, D. R. Blechschmidt, A. Yoder, Ad. Gustafson, Y. Liu, Org. Lett. 2019, 21 513-518.

[67] a) O. Chuzel, C. Magnier-Bouvier, E. Schulz, Tetrahedron: Asymmetry 2008, 19, 1010-1019; b) B. Lynikaite, J. Cvengroš, U. Piarulli, C. Gennari, Tetrahedron Lett. 2008, 49, 755-759.

[68] Q. Xia, Z. Li, C. Tan, Y. Liu, W. Gong, Y. Cui, J. Am. Chem. Soc. 2017 139, 8259-8266

[69] X. Han, Q. Xia, J. Huang, Y. Liu, C; Tan, Y. Cui, J. Am. Chem. Soc 2017, 139, 8693-8697. 
[70] Y.-M. Lin, J. Boucau, Z. Li, V. Casarotto, J. Lin, A. N. Nguyen, J. [71] J. A. Kalow, A. G. Doyle, J. Am. Chem. Soc. 2010, 132, 3268-3269. Ehrmantraut, Org. Lett. 2007, 9, 567-570. 
Entry for the Table of Contents (Please choose one layout)

Layout 1:

\section{PERSONAL ACCOUNT}

Text for Table of Contents text up to 600 characters

Layout 2:

\section{PERSONAL ACCOUNT}

Author(s), Corresponding Author(s)*

Page No. - Page No.

Title

((Insert TOC Graphic here))
((Insert TOC Graphic here))

Text for Table of Contents
Author(s), Corresponding Author(s)*

Page No. - Page No.

Title 